\title{
CELBEST Project: Design and Implementation of the First Engineering Education-specific Assessment Tool for Professional Communicative Competence
}

\author{
Cristina Fabretto \\ Research Assistant III \\ Faculty of Engineering and Applied Science, Memorial University \\ fabretto@mun.ca
}

\begin{abstract}
Following the 2010 review of engineering programs in Canada by the Canadian Engineering Accreditation Board (CEAB), the Faculty of Engineering and Applied Science at Memorial University introduced a number of changes to its undergraduate program in order to align with the new CEAB outcome-based accreditation approach [1-3]. As programs' accreditation begun to be reviewed for progress toward assessment of graduate attributes (G.A.), the 12 graduate attributes as defined by the $C E A B$ became de facto the undergraduate program outcomes at Memorial. This paper provides an overview of the Faculty's approach to the development and progressive assessment of communication skills as Graduate Attribute (G.A.: 07) in such a way that is aligned with $C E A B$ accreditation requirements while taking into account the unique challenges and opportunities inherent in its program.
\end{abstract}

Keywords: communication skills, language assessment, communicative competence approach

\section{Introduction}

The Faculty of Engineering and Applied Science at Memorial University is currently undergoing a period of tremendous growth. As part of its 2020 growth plan, the Faculty plans to increase its student body by up to 500 additional undergraduate students, hence increasing the number of graduates of its undergraduate programs from about 170 to 250 per year. Ensuring that academic and professional success is attainable for such a numerous student population is a challenge that the Faculty has proactively embraced by launching, inter alia, the CELBEST pilot research project (Canadian English Language Benchmarks for Engineering Students).

CELBEST reflects the Faculty's plan to exceed CEAB accreditation requirements for GA07 'Communication skills' while responding to the unique needs of the current and future student population of its Bachelor of Engineering cooperative program. Accordingly, the overarching aim of the project is twofold. First it seeks alignment with the definition of engineering communication skills as GA as put forward by CEAB [2], by addressing the complex problem of monitoring student progress in communication skills from enrolment to graduation. Second, it focuses on communication skills of undergraduate students as contextualized within the structure of work term placements, by addressing the challenges many students face in communicating for professional- not academic- purposes.

\section{The communicative competence approach}

In order to fulfil its aim the project identified in the models of communicative competence the rigor necessary to ensure that a systematic monitoring of progress in student skills development is possible, and the flexibility that the context of work term recruitment and placement requires. By adopting the communicative competence approach the communicative competencies that comprise 'communication skills', as expected by employers of undergraduate engineering students for work term placement, can be identified and benchmarked.

The flexibility, afforded by the framework of communicative competence regarding what to assess at what level of language ability, allows accommodating the emergence of specific competencies and increasing degrees of complexity at key stages along the continuum of the undergraduate program from enrolment to graduation. It is important to clarify, at this point, that although traditionally the models of communicative competence, as discussed below, have been studied and implemented in the context of second/ foreign language teaching, learning and assessment, their validity for describing the use of first/native language is assumed [4].

The Faculty does not enforce any form of programspecific assessment of student language and communication skills. General requirements for admission as set forth by the university apply to all of its prospective students, whether international or domestic. Since the early stages of design of the project, it was agreed that CELBEST would target the professional communication skills as relevant to any undergraduate engineering student likely challenged by the transition to engineering work term placement, regardless of their linguistic background. 
Indeed, a recent study on work term recruitment of Memorial international engineering students conducted by the author reported that good communication skills are consistently highly valued by employers but frequently poorly developed by international students, particularly at the junior level. However, evidence from the same study suggests that a high and growing number of domestic students are found to be ineffective communicators in professional settings, along the same lines as many international students. Hence the adoption of the communicative competence approach in the study of domestic and international students' communication skills was deemed justified.

\subsection{Conceptualizing of communicative competence}

Prompted initially by the perceived need to determine the feasibility and practicality of measuring what was commonly called 'communication skills' in second language teaching [5], the principles of communicative competence and the related communicative approach have been dominating the research and practice of second and foreign language teaching, learning, and assessment since the early 1980 s.

At the risk of oversimplifying a concept and a theoretical framework that generated a monumental volume of research since its introduction, it can be said that the argument at the core of the communicative approach posits that the quality of communication is depended upon the degree of mastery of the speaker of a set of interrelated competencies. Accordingly, to be truly effective, the teaching and assessment of a second language must target the development of all such competencies and not, as previously believed, solely of linguistic and grammatical knowledge.

To date, the seminal works on communicative competence remain the position paper published in 1980 by two Canadian linguists at the University of Toronto, Michael Canale and Merrill Swain [5,6], the books on assessment by Bachman [7] and Bachman and Palmer [8], and the pedagogically motivated article by Celce-Murcia and her research team [4]. Common to all three is the belief that communicative competence is comprised of four key competence clusters: (1) grammatical/linguistic competence, (2) sociolinguistic/ sociocultural competence, (3) discourse competence, and (4) strategic competence.

Briefly put, grammatical/linguistic competence comprises the syntax, morphology, lexicon, phonology and orthography in the second language. Therefore it addresses the development of all parts of the language production and reception, including pronunciation, rules of spelling and punctuation, and conventions of phrase structure [4,5]. Appropriateness of verbal and non-verbal communication to the particular context in which the language is to be used pertains to the sociolinguistic/ sociocultural competence [4]. Discourse competence targets primarily issues of cohesion and coherence and overall conversational structure in speech and writing (e.g. turn-taking system in conversation but may extend to a variety of oral genres including research report and interview, cf. Celce-Murcia et al [4]). Lastly, strategic competence refers to the "verbal and non-verbal communication strategies which enhance the efficiency of communication and, where necessary, enable the learner to overcome difficulties when communication breakdowns occur" [4]. They pertain primarily to oral interactional strategies and include, for example, stalling and timegaining strategies, but also gestures and drawing pictures [4].

Within the purview of the communicative competence approach a learner must develop all of the above mentioned competencies either through formal learning (i.e. by attending language classes) or through informal acquisition (e.g. through natural exposure and repeated practice). In order to facilitate the practical application of the communicative approach a number of projects and frameworks of reference were developed world wide. Two in particular are relevant to the development of CELBEST: the Canadian Language Benchmark (CLB) of second language proficiency, developed by the Centre for Canadian Language Benchmarks [9-14] and the Common European Framework of Reference for Language (CEFR) developed by the Council of Europe [15-17].

\subsection{Frameworks of reference of communicative competence}

While CELBEST has been designed with the CLB model in mind, a relatively recent trend in Canada seem to increasingly favour CEFR as framework of reference for the design of second language curricula and assessment tools for a variety of contexts [18-20]. Very similar in nature, the two models share the same theoretical underpinning (i.e. the communicative approach).

Accordingly, in both models the learner's language ability is represented as evolving along a hypothetical continuum (or scale), subdivided into 12 level/benchmarks and three stages in the CLB and in 6 levels and three stages in the CEFR. Progress along the continuum and between each level/stage is conceptualized as the learner's ability to perform increasingly complex language tasks in increasingly demanding contexts of communication.

The learner will progress in terms of his or her degree of ability to succeed in performing a given language task [10]. It is important to clarify what constitutes a language task in the communicative approach as intended in CLB and CEFR. Language task is defined as what the learner is expected to be able to do with the language at each of the 
12 benchmarks (CLB) or 6 levels (CEFR). A learner can be considered to be at a given benchmark/level when that learner meets the criteria and the expectations as described and defined in terms of performance descriptors (Can Do descriptors) assigned to that benchmark/level.

Each performance descriptor represents a clearly identifiable, directly observable, and, hence, measurable performance outcome of learner ability on which assessment tools can be designed and teaching/learning strategies can be developed [19-13, 22-27]. A number of examples of Can Do performance descriptors have been developed for either the CLB or the CEFR. However, instructors and institutions are encouraged to create their own list of language tasks and scale of performance descriptors specifically tailored to the needs of the learner and uniquely relevant to contexts in which the learner will be expected to perform. It is this flexibility that made the CLB/CEFR such a formidable resource in the development of the CELBEST project.

\section{The CELBEST Project}

Relevant literature in the field of engineering education and accreditation shows that professional skills, and particularly communication skills, have become a cornerstone of employability and competitiveness for new graduates [2, 28-33]. Case in point, the literature on 'graduate attributes' in general, and 'professional skills', including 'communication skills', in particular, has burgeoned in recent years [e.g. 34, 35-40]. To date, however, no comprehensive and viable solution has been identified to the problem of inadequate communication skills in students' pre-graduation employment. Acknowledging that poor communication skills is a growing obstacle to student overall success in a cooperative program, such as the one at Memorial, with CELBEST the Faculty took the first step to narrowing that gap.

The overarching goal of the CELBEST project is to improve our knowledge of the subject of performance in communication as it relates specifically to the pregraduation employment of undergraduate co-op engineering students. CELBEST will have as its primary objective the benchmarking of the communicative competencies expected of undergraduate engineering students for work term placement, first, and at-graduation employment, second (Cf. CEAB, graduate attributes).

\subsection{The CELBAN template}

Modelled, in part, on the widely successful Canadian English Language Benchmarks for Nurses (CELBAN) [41] the framework of reference for CELBEST will be the Canadian Language Benchmarks (CLB) $[9,10]$.
In the design of CELBEST, CELBAN was used as a model and template to be adapted to the specific needs and contexts as defined for CELBEST. Central to CELBAN is the assessment of professional communication skills of internationally educated nurses (IENs) [41]. Its assessment tool (the CELBAN Test) provides a realistic measure of the language skills required to work as a nurse in a Canadian workplace by assessing the communication skills of nurses using language tasks linked to nursing practice [41].

CELBAN was designed to be is highly specific, efficient, economical. Analogously, CELBEST addresses the complex problem of assessing the professional communication skills by focusing on real-life English language professional demands of undergraduate engineering students. Like CELBAN, CELBEST seeks alignment with industry professional standards and best practice. The identification and use of language tasks as relevant to their specific professional context and practice, is instrumental in meeting the language needs of the profession at the level of complexity that is appropriate to an undergraduate student.

The research design and methodology of CELBAN entailed mixed methods of data collection and multiple data sources. Data collection instruments included survey questionnaires (designed to yield a ranking of language tasks described by the CLB document), focus groups with different stakeholders (ranging from nurses' employers to supervisors and colleagues), interviews, and direct observation of nurses on the job. As a result, 37 highly relevant language tasks were identified. They were used to inform the design of the CELBAN Test, currently administered to internationally educated nurses across Canada.

\subsection{Towards the design of CELBEST assessment tools}

To date, a preliminary list of 30 relevant language tasks was compiled for CELBEST. The compilation of the list took into account all four language skills (Speaking, Listening, Reading, Writing) in four CLB [10] specific competency areas in which the work term related communication of undergraduate engineering students is believed to take place:

- social interaction: interacting in an interpersonal social situation, in speech or writing.

- following and giving instructions: in speech or writing.

- suasion: persuading others, or reacting to suasion to do something, in speech or writing.

- information: exchanging, presenting and discussing information, ideas, opinions, feelings; telling stories, describing, reporting, arguing, etc., in speech or writing. 
At this time, CELBEST is in the second of three development phases. Ad hoc questionnaires and semistructured interview protocols have been designed to elicit detailed information concerning students' language tasks in work term settings from participants representing academia, industry, and undergraduate student body. Findings from this will be used to design a pilot version of benchmark-based assessment tools, which will be pilottested and revised in Phase III, and are expected to be fully operational in early 2017.

As part of the CELBEST project, three ad hoc assessment tools will be designed to be administered to all undergraduate students upon arrival (pre-WT1), at midprogram (WT3), and at graduation (Academic Term 7 or 8), respectively. To serve its purpose, however, CELBEST will not assess progress from Basic, Intermediate and Advanced as defined in CLB or CEFR. Like CELBAN, CELBEST will identify and subsequently assess three specific threshold benchmarks of language and communication competence. Each benchmark will be intended as threshold of adequate competence expected of the student by employers at each stage of advancement of the student's program of study. Analogously, the four competency areas in CLB cited above, will be tailored to reflect the professional context and roles of the student at increasing degrees of seniority within the program.

\section{Conclusion}

The CELBEST project was conceived as a stand-alone project targeting students' shortfall in communication skills necessary for pre-graduation employment. However, results from this project are expected to significantly improve our knowledge of the subject and provide implications of interest to the Engineering academic, student, and professional community, including provide valuable applications to improve quality and outcomes of engineering co-op programs in Canada.

Furthermore, data and information from CELBEST can be used to progressively sharpen education and training strategies to ensure that competency targets are reached and student retention and success in strengthened. As a result, credit and non-credit courses as well as informal training initiatives may be developed in response to identified key areas of improvement as well as specific lacunae in students' knowledge and performance.

Most importantly, data and information from CELBEST can inform the definition of 'effective communication' and 'collaboration' from nebulous components of 'graduate attributes' to specific and explicit outcomes of engineering education at Memorial, in line with the outcome based approach adopted by CEAB to evaluate engineering programs in Canada.

\section{References}

[1]Spracklin-Reid, D., and A. Fisher, "Curriculum mapping in Engineering education: Linking attributes, outcome and assessments", Canadian Engineering Education Association conference (CEEA14) Calgary, Alberta, 2014.

[2]C.E.A.B., "Accreditation Criteria and Procedures", Ottawa, ON: Canadian Engineering accreditation Board - Engineers Canada, 2014, pp. 118.

[3] C.E.A.B., "Canadian Engineering Accreditation Board. Accreditation Criteria and Procedures ", Ottawa, ON. : Engineers Canada, 2012-2013, pp. 114.

[4]Celce-Murcia, M., Z. Dörnyei, and S. Thurrell," Communicative competence: A pedagogically motivated model with content specifications", Issues in Applied linguistics Vol. 6, No. 2, 1995, pp. 5-35.

[5]Canale, M., and M. Swain," Theoretical bases of communicative approaches to second language teaching and testing", Applied linguistics Vol. 1, No. 1, 1980.

[6]Canale, M., "From communicative competence to communicative language pedagogy", Language and communication, London ; New York: Longman, 1983, pp. 147.

[7]Bachman, L.F., Fundamental considerations in language testing, Oxford, UK: Oxford University Press, 1990.

[8]Bachman, L.F., and A. Palmer, Language assessment in practice: Developing language assessments and justifying their use in the real world, New York: Oxford University Press, 2010.

[9]Centre for Canadian Language Benchmarks, "Relating Canadian Language Benchmarks to Essential Skills: A Comparative Framework.", Ottawa: CCLB, 2005.

[10]Centre for Canadian Language Benchmarks, "Appropriate Uses of the Canadian Language Benchmarks Guidelines and Assessment Tools", Ottawa: Centre for Canadian Language Benchmarks, 2008.

[11]Centre for Canadian Language Benchmarks, "Canadian Language Benchmarks. English as a Second Language For Adults.", Ottawa, ON: Citizenship and Immigration Canada, 2012, pp. 235.

[12]Centre for Canadian Language Benchmarks, "Canadian Language Benchmarks Can Do Statements", Ottawa, ON: Centre for Canadian Language Benchmarks, 2013.

[13]Centre for Canadian Language Benchmarks, "Canadian Language Benchmarks: ESL for Adult Literacy Learners (ALL)", Ottawa, ON: Centre for Canadian Language Benchmark, 2015, pp. 150.

[14]Centre for Canadian Language Benchmarks, "Theoretical Framework for the Canadian Language Benchmarks and Niveaux de Compétence Linguistique Canadiens", Ottawa, ON: CCLB, 2015.

[15]Council of Europe, "A Common European Framework of Reference for Languages: learning, teaching, assessment", Cambridge: Cambridge University Press, 2001.

[16]Council of Europe, "Common European Framework of Reference for Languages: Learning, Teaching, Assessment (CEFR)", Strasbourg., 2014. 
[17]Council of Europe, "Structured Overview of All CEFRrelated Scales. ", European Language Portfolio, Strasbourg Cedex, 2001.

[18]Macdonald, J., and L. Vandergrift, "The CEFR in Canada": PowerPoint document presented at the Council of Europe's Intergovernmental Policy Forum: The Common European Framework of Reference for Languages (CEFR) and the development of language policies: Challenges and responsibilities, Strasbourg, France, 2007.

[19]Council of Ministers of Education Canada, "Working with the Common European Framework of Reference for Languages (CEFR) in the Canadian Context. Guide for Policymarkers and Curriculum Designers. ", Toronto, ON: CMEC, 2010.

[20]Vandergrift, L., Proposal for a common framework of reference for languages for Canada, Ottawa: Canadian Heritage, 2006.

[21]Pépin, C., "Common European Framework of Reference for Languages: Learning, teaching, assessment and Canadian Language Benchmarks 2000/Niveaux de compétence linguistique canadiens 2006. An overview of concepts, structures and applications.", Ottawa: Centre for Canadian Language Benchmarks, 2008.

[22]Stewart, G., K. Geraci, and P. Nagy," Essential skills and Canadian language benchmarks: Considerations in comparing conceptual frameworks", Ottawa: Centre for Canadian Language Benchmarks, 2004.

[23]Centre for Canadian Language Benchmarks, "Theoretical Framework for the Canadian Language Benchmarks.", Ottawa, ON: CCLB, 2013, pp. 82.

[24]Davidson, F., and G. Fulcher," The Common European Framework of Reference (CEFR) and the design of language tests: A matter of effect", Language Teaching Vol. 40, No. 03, 2007, pp. 231-241.

[25]North, B.," Putting the Common European Framework of Reference to good use", Language Teaching Vol. 47, No. 02, 2014, pp. 228-249.

[26]Vandergrift, L.," The CEFR in Practice", Canadian Modern Language Review Vol. 71, No. 4, 2015, pp. 507-509.

[27]North, B., The CEFR in practice, Cambridge: Cambridge University Press, 2014.

[28]Borrego, M., and J. Bernhard," The emergence of engineering education research as an internationally connected field of inquiry", Journal of Engineering Education Vol. 100, No. 1, 2011, pp. 14-47.

[29]Sheppard, S., K. Macatangay, A. Colby, and W.M. Sullivan, Educating engineers: Designing for the future of the field: Jossey-Bass San Francisco, CA, 2009.

[30]Subcommittee on Attributes and Competencies, "Graduate Attributes at the University of Alberta. Final report (Draft)": University of Alberta, 2013.

[31]NAE, Educating Engineers: Preparing 21st Century Leaders in the Context of New Modes of Learning: Summary of a Forum: The National Academies Press, 2013.

[32]NAE, "Educating the Engineer of 2020: Adapting Engineering Education to the New Century": The National Academies Press, 2005.

[33]NAE, The Engineer of 2020: Visions of Engineering in the New Century: The National Academies Press, 2004.
[34]Caron, B., G. Gopakumar, D. Dysart-Gale, and M. Harsh," Navigating a Constitutional Moment: Reflections on Implementing Graduate Attributes in Canadian Engineering Education", Engineering Studies Vol. 6, No. 1, 2014, pp. 4461.

[35]Cloutier, G., R. Hugo, and R. Sellens," Mapping the Relationship Between the CDIO Syllabus and the CEAB Graduate Attributes: An Update", International Journal of Quality Assurance in Engineering and Technology Education (IJQAETE) Vol. 2, No. 2, 2012, pp. 34-44.

[36]Engineers Mobility Forum, "Graduate Attributes and Professional Competencies Ver. 2.", 2009.

[37]Garcia Fernandez, M., and E. Tovar Caro, "The experience of implementing a communication skills assessment in the first year course for undergraduate computing engineering students: A tool for further development of an international curriculum", IEEE Global Engineering Education Conference (EDUCON) - "Learning Environments and Ecosystems in Engineering Education", Amman Jordan: IEEE, 2011, pp. 1081-1087.

[38]Goh, S., and N. Baker, "Need for a global accord for the postgraduate learning of engineers", Proceedings of the IACEE2012 13th World Conference on Continuing Engineering Education (WCCEE 2012): International Association for Continuing Engineering Education, 2012. [39]Harris, J., A. Steele, and D. Russell," Progress on defining the CEAB graduate attributes at Carleton University", Proceedings of the Canadian Engineering Education Association, 2011.

[40]Kozanitis, A., and G.M. Cloutier," Using authentic assessment in satisfying CEAB's new graduate attributes accreditation criteria", Proceedings of the Canadian Engineering Education Association, 2011.

[41]CELBAN Research Team, "Benchmarking the English Language Demands of the Nursing Profession Across Canada", Winnipeg, MA: Centre for Canadian Language Benchmarks Red River College Language Training Centre, 2002. 